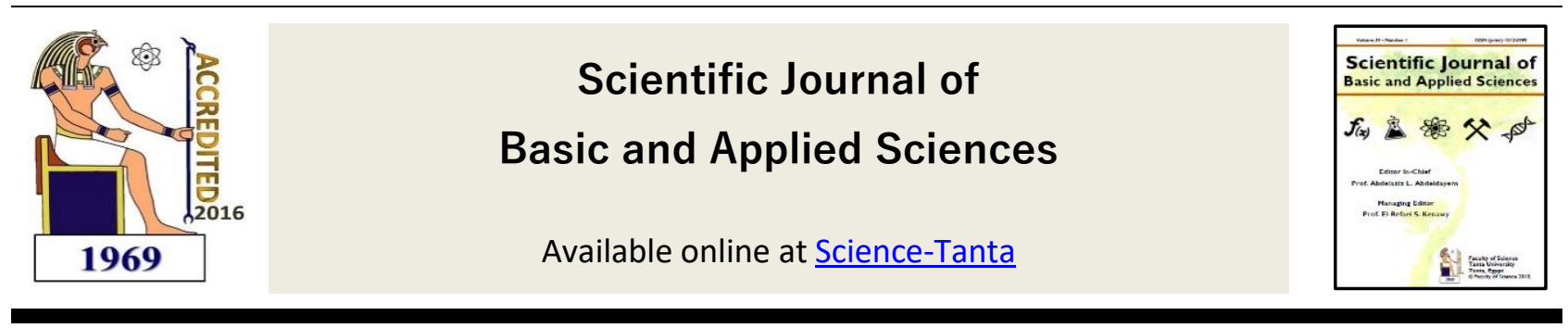

Research Article

MICROBIOLOGY

\title{
Evaluation the biological activities of chitosan and O-carboxymethyl chitosan extracted from crab shell waste
}

\author{
Shimaa H. El-Sapagh ${ }^{1}$, Wagih A. El-Shouny ${ }^{1}$, El-Refaei S. Kenawy ${ }^{2}$, Samia A. Shabana ${ }^{1}$ \\ 1. Botany Department, Microbiology Unit, Faculty of Science, Tanta University, Tanta 31527, Egypt. \\ 2. Chemistry Department, Polymer Research Unit, Faculty of Science, Tanta University, Tanta 31527, Egypt. \\ * Correspondence: Shaimaa H. El-Sapagh; Botany Department, Microbiology Unit, Faculty of Science, Tanta University,
} Tanta 31527, Egypt.

KEY WORDS

Chitosan;

O-carboxymethyl

chitosan;

Antibacterial activity;

Cytotoxicity;

Artificial wound infection.

\begin{abstract}
The main objective of this study is to prepare chitosan and Ocarboxymethyl chitosan and evaluate their biological activities in vitro. In this study, twenty crab shells were collected from locally fish restaurant in the city of Tanta, Egypt. Chitosan has been produced from crab waste by chemical method then modified by introducing carboxymethyl group into its back bone. The antibacterial activity of chitosan and O-carboxymethyl chitosan was tested against multidrugresistant bacteria by cut-plug method. It was found that the antibacterial activity of modified chitosan was better than the native one. On the other hand, the cytotoxicity of chitosan and O-carboxymethyl chitosan was tested on liver carcinoma cell line HEPG-2 and normal human fibroblast cells (WISH 38). They recorded cytotoxic activities on liver carcinoma cell line, while their toxicities on normal human fibroblast cells were negligible. Finally, their antibacterial activity was evaluated in vivo; the results showed that they were highly active and safe in the treatment of wound infection.
\end{abstract}

\section{Introduction}

Infectious diseases are still the second leading cause of death worldwide. Infectious diseases and antimicrobial resistance have become widespread problems (Florescu et al., 2017). Therefore, therapeutic compounds that can either inhibit the growth of pathogens or kill them and have no or least toxicity to host cells are considered as candidates for developing new antimicrobial drugs. Because of the problems associated with the use of conventional antimicrobial agents, the idea of polymeric antimicrobial agents appeared to be an attractive alternative. Compared with conventional antimicrobial agents of low molecular weight, polymeric antimicrobial agents have the following advantages that they are non volatile and chemically stable. Polymeric antimicrobial agents may enhance the efficacy of some existing antimicrobial agents and minimize the environmental problems accompanying the residual toxicity of the agents in addition to prolonging their life time (Munoz-Bonilla et al., 2014). 
One of the most interesting polymeric antimicrobial agents is chitosan, chitosan attracts the attention of the scientists in the last few years, because of its special properties including biocompatibility, biodegradability and non-toxicity. Chitosan is a technologically important polysaccharide biopolymer. Chemically, it is a high molecular weight linear polycationic heteropolysaccharide consisting of two monosaccharides, N-acetyl-D-glucosamine and $\mathrm{D}$-glucosamine, linked together by $\beta$ $(1 \rightarrow 4)$ glycosidic bonds. The relative amount of the two monosaccharides in chitosan may vary, giving samples of different degrees of deacetylation (75-95\%), molecular weights (50-2,000kDa), viscosities and pKa values. Therefore, the term chitosan does not refer to a uniquely defined compound; it merely refers to a family of copolymers with various fractions of acetylated units. Chitin and chitosan are potential biomaterials for biotechnological industries and tissue engineering, due to many characteristics, including their polyelectrolyte and cationic nature, the presence of reactive groups, high adsorption capacities, bacteriostatic and fungistatic influences (Xiang et al., 2018).

Chitosan has been widely used for different biological and biomedical applications such as antimicrobial, hypo-cholesterollemic, antitumor, anti-inflammatory, antioxidant, excluding toxins from the intestine, radioprotective properties, preventing tooth decay and immunity enhancing activities. It is also used in water treatment and wound healing (Escarcega Galaz et al., 2018).

However, chitosan has many applications, its activity is limited above $\mathrm{pH}$ 6.5. Above $\mathrm{pH}$ 6.5, chitosan starts to lose its cationic nature. Therefore, special attention was paid to chemical modification of chitosan forming several derivatives with high solubility in water. Chitosan contains three main types of reactive functional groups, an amino/acetamide group as well as both primary and secondary hydroxyl groups. These functional groups give it a considerable chance of chemical modification (Inmaculada et al., 2010).
The present study was conducted to prepare chitosan and O-carboxymethyl chitosan from crab shell waste by chemical method then, investigate their antibacterial activities against multidrug-resistant pathogenic bacteria isolated from human wounds. This study also aimed to evaluate their cytotoxicity in vitro. Then investigate their antibacterial activities on experimental animals in vivo.

\section{Materials and Methods}

\subsection{Reagents:}

Sodium hydroxide, hydrochloric acid, acetone, methanol and sodium hypochlorite were purchased from El Nasr Pharmaceutical Chemicals. Acetic acid was purchased from AIPHA CHEMIKA. Isopropanol was purchased from Merck-Schuchardt, Hohenbrunn, Germany. Monochloroacetic acid was purchased from Aldrich.

\subsection{Test bacteria:}

Five antibiotic-resistant bacterial isolates were isolated from wounds of patients in Department of Burns at Tanta University Hospitals. These isolates included Gram-negative bacteria Escherichia coli, Proteus mirabilis and Pseudomonas aeruginosa and Gram-positive bacteria Staphylococcus aureus and Streptococcus pyogenes.

\subsection{Experimental animals:}

Thirty-five male and female mice with initial age of 6-8 weeks and weighed 20-23 g were used throughout the study. Mice were given food and water; and housed in the animal house in the Faculty of Science, Tanta University.

\subsection{Extraction of chitosan from crab shells:}

The raw materials used in this work were the exoskeleton of crabs, which collected from locally fish restaurant in the city of Tanta, Egypt. The process of extraction of chitin from crab shells was carried out with four basic steps. Chitosan was derived from shells with demineralization, deproteinization, discoloration and deacetylation according to 
the method described by No et al. (2003). Then the obtained chitosan purified. The purification process was designed in three steps; dissolving chitosan in $1 \%$ acetic acid; removal of any insoluble materials by filtration and reprecipitation of chitosan with $1 \mathrm{~N} \mathrm{NaOH}$. The purified chitosan was dried in an oven at $60^{\circ} \mathrm{C}$ for $4 \mathrm{~h}$.

\subsection{Synthesis of $O$ - carboxymethyl chitosan}

Synthesis of O-carboxymethyl chitosan was carried out according to method described by Zhu et al. (2006). Chitosan was first activated by soaking it in an alkaline solution $(\mathrm{NaOH}$ $40 \%$ ) for $24 \mathrm{~h}$ at room temperature. The concentration of chitosan was $4 \%(\mathrm{w} / \mathrm{v})$ in $40 \%(\mathrm{w} / \mathrm{v})$ solution of $\mathrm{NaOH}$. The activated chitosan was then reacted with mono-chloroacetic acid in solid form. The concentration of mono-chloro-acetic acid used was $1: 1$ by weight in isopropanol and water; the reaction was carried out at $30^{\circ} \mathrm{C}$ for $24 \mathrm{~h}$. At the end of the reaction, the product was precipitated by acetone, filtered, washed with acidified water/alcohol, then with mixture of distilled water/alcohol until the washing water was neutral. Water was removed by acetone and the product was dried.

2.6. Characterization techniques of chitin, chitosan and $O$ - carboxymethyl chitosan:

a) The infrared spectra (IR):

It was carried out using infrared spectrophotometer Perkin-Elmer1430. Small discs were made from the mixture of about 1 $\mathrm{mg}$ of the tested material and $300 \mathrm{mg}$ of pure $\mathrm{KBr}$, followed by pressing in to a disc and used for determination the infrared spectra. The measurements were carried out at infrared spectra between 400 and $4000 \mathrm{~cm}^{-1}$.

The degree of acetylation (DA) of the chitin was calculated using the following equation (Majtan et al., 2007):

$$
\text { DA }(\%)=(\mathbf{A} 1655 / A 3450) \times 100
$$

The degree of deacetylation (DD) of chitosan was calculated according to the following equation (Baxter et al., 1992):

$$
\text { DD }(\%)=100-[(\mathbf{A 1 6 5 8} / \mathbf{A 3 4 5 0}) \times 115]
$$

\section{b) X-Ray Diffraction (XDR):}

$X$-ray diffraction peaks were measured at 40 $\mathrm{kv}, 30 \mathrm{~mA}$ and $2 \theta$ with a scan angle from $5^{\circ}$ to $90^{\circ}$. X-ray diffraction was carried out using GNR-X-ray diffractometer: model APD 2000 PRD with $\mathrm{Cu}$ anode.

The crystalline index (Cr I) of chitosan was calculated using the following equation (Liu et al., 2012):

\section{$\mathrm{Cr} \mathbf{I}_{110}=\left[\left(\mathbf{I}_{110}-\mathbf{I}_{\mathbf{a m}}\right) / \mathbf{I}_{110}\right] \times 100$}

$\mathrm{I}_{110}=$ the maximum intensity at $2 \theta=20^{\circ}$

$\mathrm{I}_{\mathrm{am}}=$ the intensity of amorphous diffraction at $2 \theta=16^{\circ}$

\subsection{Screening the antibacterial activity of tested Polymers:}

Cut-plug method recorded by Pridham et al. (1956) was employed to determine the antibacterial activity of the tested polymers.

\subsection{In vitro cytotoxicity of tested polymers by Sulfo-Rhodamine-B assay (SRB):}

Chitosan and O-carboxymethyl chitosan were evaluated for their cytotoxicity using tissue culture technique. Human tumor cell line (liver HEPG-2) and normal human fibroblast cells were obtained frozen in liquid nitrogen ($80^{\circ} \mathrm{C}$ ) from the American Type Culture Collection (ATCC, Rock Ville, MD). The tumor cell line was maintained by serial subculturing. Cells were cultured in DMEM medium supplemented with $10 \%$ fetal bovine serum and $100 \mathrm{mg} / \mathrm{l}$ penicillin (Hi-media, India). The cells were maintained under $97 \%$ humidity in a biological incubator at $37^{\circ} \mathrm{C}$ in a $5 \%$ of carbon dioxide atmosphere. The cell numbers were determined with a hemocytometer and the viability was assessed using Sulfo-Rhodamine-B (SRB) method.

Potential cytotoxicity of the tested compounds was studied using the method of Skehan $\boldsymbol{e t} \boldsymbol{a l}$. (1990).

\section{Calculation:}

The percentage of cell survival was calculated as follows:

$$
\begin{aligned}
& \text { Cell viability } \%=\frac{O D(\text { treated cells })}{\text { OD control cells }} \times 100 \\
& O D=\text { optical density }
\end{aligned}
$$


The graph was plotted with cell viability against various concentrations of the compound. The $\mathrm{IC}_{50}$ values indicated the concentration of tested compound required to produce $50 \%$ inhibition of cell growth. The experiment was repeated three times for each tested polymer.

\subsection{In vivo evaluation the antibacterial effect of chitosan \& O-carboxymethyl chitosan on P. aeruginosa infection}

Mice were anesthetized with a combination of ketamine-HCL $(90 \mathrm{mg} / \mathrm{kg})$ and xyla-ject (10 $\mathrm{mg} / \mathrm{kg}$ ) administrated intra-peritoneal. At the back of mice, the skin was shaved with electric clippers with a surgical blade (0.1 $\mathrm{mm})$. The clipped area was cleaned and then disinfected with povidone-iodine (10\%) (Niksa et al., 2010). Full-thickness circular segments (epidermis and dermis) 10 X11 mm in diameter; were excised from the skin using a punch biopsy. The dissected area was disinfected with povidone-iodine betadine $(10 \%) .50 \mu \mathrm{l}$ of the bacterial inoculum $\left(10^{8} \mathrm{CFU} / \mathrm{ml}\right)$ was injected subcutaneously into sites of the dissected animals back of each tested mice group. The biopsy wounds were covered with sterile, non-adhesive dressed cotton and adhesive medical tapes.

\subsection{Treatment of induced wounds of mice groups with the tested polymers.}

To determine the effectiveness of polymers for the superficial treatment of artificial wound infection, four groups of mice (each group contain five mice) were subcutaneously injected with sub-lethal dose $\left(10^{8}\right.$ CFU/ml/mouse) of Pseudomonas aeruginosa. First group of mice was treated with ointment preparation of chitosan on the wounded area; second group of mice was treated with $\mathrm{O}$ carboxymethyl chitosan on the wounded area. The third group was treated with fusidic acid ointment as positive control. Fourth group was treated with ointment base as negative control. The appearance of the wounded area was recorded by digital imaging. The diameter of wounded area was recorded in $1^{\text {st }}, 5^{\text {th }}, 10^{\text {th }}$, $14^{\text {th }}, 17^{\text {th }}, 21^{\text {st }}$ day after each treatment until recovery.

\subsection{Histopathological examination of mice skin tissues:}

Histopathological examination was carried out for five mice, the first one represented the healthy mice skin tissues as a negative control, the second one was for infected mice skin tissues with $P$. aeruginosa (untreated) that considered as a positive control. The third one represented mice skin tissues treated with chitosan preparing ointment. The fourth one was for mice skin tissues treated with $\mathrm{O}$ carboxymethyl chitosan, and the fifth one was for mice skin tissues treated with fusidic acid ointment. This examination was carried out according to the procedures of Bancroft $\boldsymbol{e t} \boldsymbol{a l}$. (1996)

\subsection{Statistical analysis:}

All experiments were done in triplicates and the results were expressed as means \pm and standard deviation. Analysis of variance (ANOVA one way) was established to assess the significant variation at $\mathrm{P} \leq 0.05$ level of significance (Pipkin, 1984).

\section{Results}

Crab shells weighed for a total weight of 67.6 $\mathrm{g}$, where the individual shell weights varied from $2.8 \mathrm{~g}$ to $4.1 \mathrm{~g}$. The selected lots were dried in an oven at $60^{\circ} \mathrm{C}$ for $6 \mathrm{~h}$. After drying, the total weight of the samples was about $57.76 \mathrm{~g}$, having suffered a mass loss of $14.5 \%$ compared to the total weight of the samples before drying. The shells were grounded and sieved. The isolation of chitin from the crab shells was carried out with demineralization, deproteinization and discoloration.

After the demineralization, deproteinization and discoloration, it was found that the chitin content of crab shells was $28.4 \%$ (16.3 g) of the grounded dry weight. The chitosan was obtained from deacetylation of chitin in alkaline solution. During this reaction, the acetamide groups (-NHCOCH3) of chitin were converted into amino groups (-NH2) leading to chitosan. As the reaction of chitin deacetylation was more aggressive due to high alkalinity and temperature employed, the chitosan yield from the chitin was found to be $74.2 \%$ (12.1 g). 
According to the Infrared spectroscopy of chitin, the degree of acetylation was $99.12 \%$. Infrared spectroscopy of chitin was shown in fig. 1. On analyzing the spectra of chitin, there was band at $3437 \mathrm{~cm}^{-1}$ which attributed to $\mathrm{NH}_{2}$ and $-\mathrm{OH}$ groups stretching vibration. The band at $2856 \mathrm{~cm}^{-1}$ was for $\mathrm{C}-\mathrm{H}$ group. The characteristic carbonyl $\mathrm{C}=\mathrm{O}$ stretching of chitin at $1670 \mathrm{~cm}^{-1}$ was attributed to the vibrations of the amide I band. The presence of band at $1558 \mathrm{~cm}^{-1}$ corresponds to $\mathrm{N}-\mathrm{H}$ of amide II. The vibration bands at $1091 \mathrm{~cm}^{-1}$ showed -C-O group vibration inside chitin ring.

According to the Infrared spectroscopy of chitosan, the degree of deacetylation was $86.6 \%$. The spectrographs of chitosan were shown in fig. 2. It was an evident from the spectra that there were significant changes in the band at $1426 \mathrm{~cm}^{-1}$ where a reduction in the peak was observed. The intensity of the band at $1637 \mathrm{~cm}^{-1}$ associated with carbonyl group $(\mathrm{C}=\mathrm{O})$ (amide I band) decreased as the degree of deacetylation of the chitosan increased. The band at $3444 \mathrm{~cm}^{-1}$ was corresponding to $-\mathrm{NH}_{2}$ group and $\mathrm{OH}$ group. The peaks at $898 \mathrm{~cm}^{-1}$ referred to pyranose ring, $1155 \mathrm{~cm}^{-1}$ referred to the glycosidic linkage (C-O-C). The peak at $1384 \mathrm{~cm}^{-1}$ referred to the angular deformation and symmetry of $-\mathrm{CH}_{3}$ group. The band at $1429 \mathrm{~cm}^{-1}$ referred to $\mathrm{CH}_{2}$ group in $\mathrm{CH}_{2} \mathrm{OH}$. The peak at $1595 \mathrm{~cm}^{-1}$ referred to amide II band $\left(\mathrm{NH}_{2}\right.$ in $\left.\mathrm{NHCOCH}_{3}\right)$. The band at 2853 $\mathrm{cm}^{-1}$ was attributed to the $-\mathrm{C}-\mathrm{H}$ stretching links.

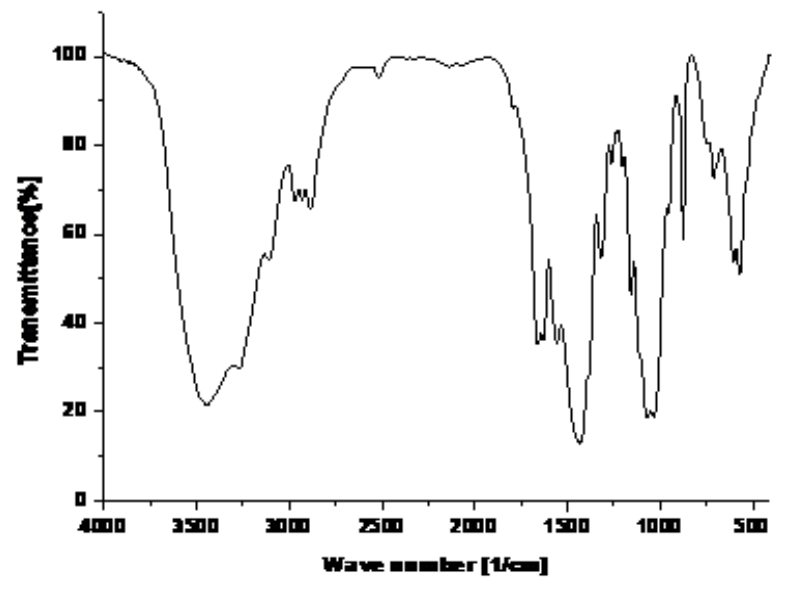

Figure 1: IR spectrum of chitin in the region 400$4000 \mathrm{~cm}^{-1}$

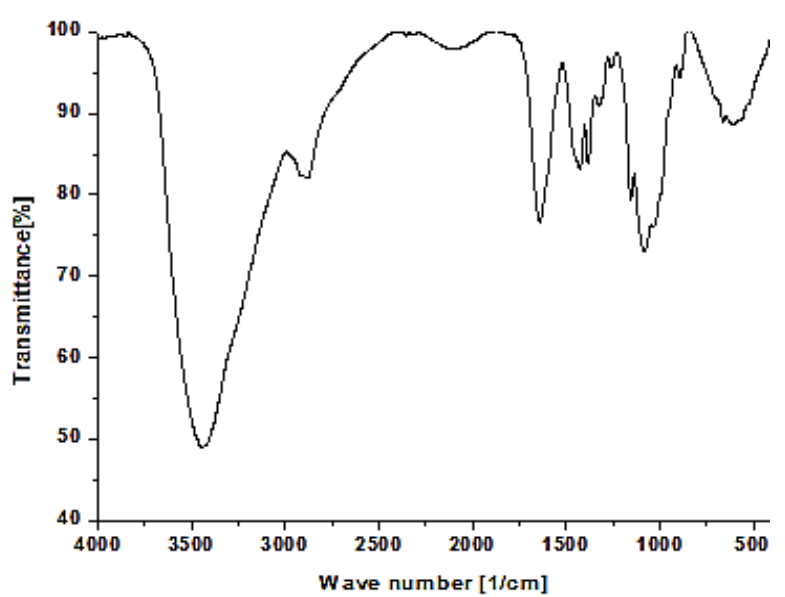

Figure 2: IR spectrum of chitosan in the region $400-4000 \mathrm{~cm}^{-1}$.

X-ray diffraction of chitosan was carried out in the range of $2 \theta=5^{\circ}$ to $2 \theta=90^{\circ}$. The reflection of the crystalline peaks was at $10.0^{\circ}$ and $20.0^{\circ}$ as identified from the diffraction patterns (Fig. 3). The degree of crystallinity of chitosan was found to be $56.25 \%$.

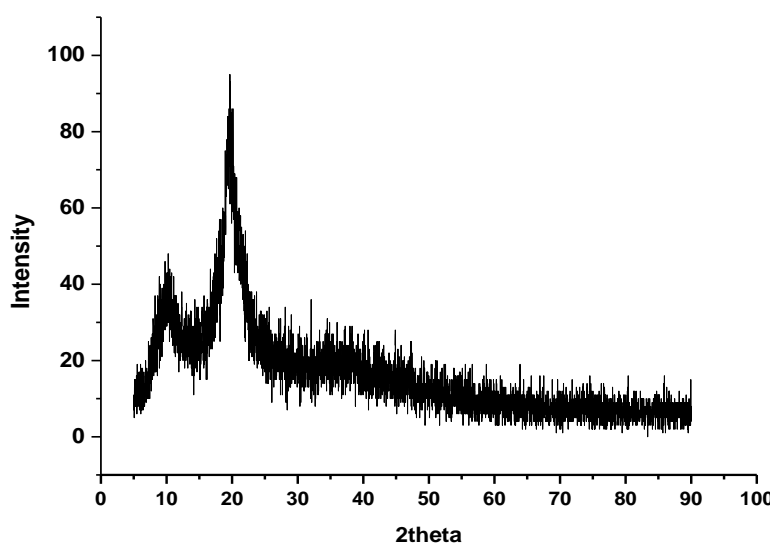

Figure 3: X-ray diffraction of chitosan.

O-carboxy methyl chitosan has been synthesized by direct alkylation. The synthesis of O-carboxymethyl chitosan has been confirmed by FTIR spectroscopy. The infrared spectrum of O-carboxymethyl chitosan showed the intrinsic peak of $-\mathrm{COOH}$ group at $1741 \mathrm{~cm}^{-1}$. The broad peak in $\mathrm{O}$ carboxymethyl chitosan at $3445-3269 \mathrm{~cm}^{-1}$ was caused by both $\mathrm{O}-\mathrm{H}$ and $\mathrm{N}-\mathrm{H}$ stretching vibrations. The peaks at 1629 and $1556 \mathrm{~cm}^{-1}$ were corresponding for $\left(-\mathrm{NH}^{+}\right)$group. The spectrum of O-carboxymethyl chitosan showed also a peak at $1430 \mathrm{~cm}^{-1}$ which referred to the $-\mathrm{CH} 2-\mathrm{COOH}$ group. The bands at 1157 and $1033 \mathrm{~cm}^{-1}$ were corresponding for $-\mathrm{C}-\mathrm{O}$ group (Fig. 4). 


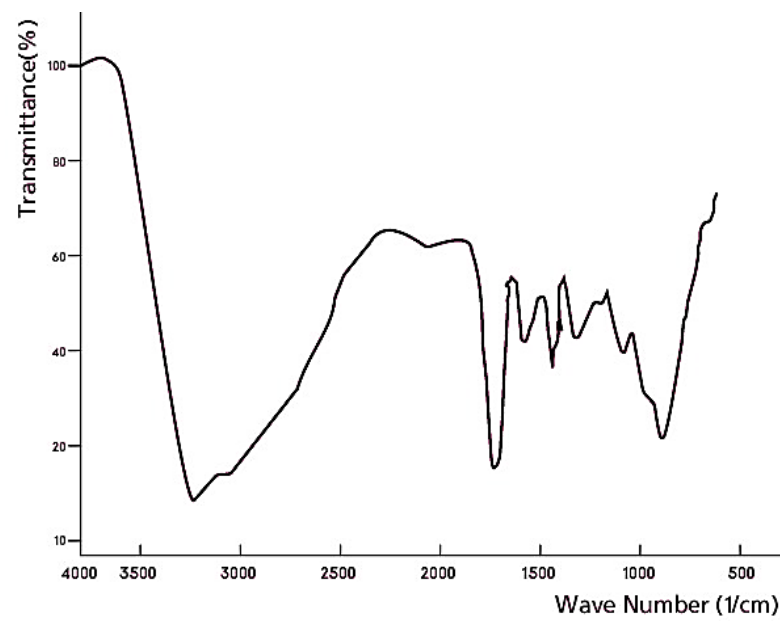

Figure 4: I.R spectrum of O-carboxymethyl chitosan in the region $400-4000 \mathrm{~cm}^{-1}$.
Chitosan (Ch) showed week inhibition zone for Gram-positive bacteria, $11.9 \mathrm{~mm}$ for Staphylococcus aureus; $11.0 \mathrm{~mm}$ for Streptococcus pyogenes and showed high inhibition zone for Gram-negative bacteria, $19.3 \mathrm{~mm}$ for Pseudomonas aeruginosa; 18.3 $\mathrm{mm}$ for Proteus mirabilis and $18.0 \mathrm{~mm}$ for Escherichia coli. O-carboxymethyl chitosan (O-CMC) showed moderate inhibition zone of $14 \mathrm{~mm}$ for Staphylococcus aureus; showed $13.6 \mathrm{~mm}$ inhibition zone for Streptococcus pyogenes and showed high inhibition zones 28.3, 27 and $26 \mathrm{~mm}$ for Gram-negative bacterial isolates Pseudomonas aeruginosa, Escherichia coli and Proteus mirabilis respectively (Table 1).

Table (1): Antibacterial potentialities of chitosan and O-carboxymethyl chitosan on multi-drug resistant bacteria

\begin{tabular}{cccccc}
\hline \multirow{2}{*}{ Polymer } & \multicolumn{5}{c}{ Mean values of inhibition zones (in mm) against bacteria } \\
\cline { 2 - 6 } & $\begin{array}{c}\text { Staphylococcus } \\
\text { aureus }\end{array}$ & $\begin{array}{c}\text { Streptococcus } \\
\text { pyogenes }\end{array}$ & $\begin{array}{c}\text { Pseudomonas } \\
\text { aeruginosa }\end{array}$ & $\begin{array}{c}\text { Proteus } \\
\text { mirabilis }\end{array}$ & $\begin{array}{c}\text { Escherichia } \\
\text { coli }\end{array}$ \\
\hline Chitosan & $11.9 \pm 0.5$ & $11.0 \pm 0.0$ & $19.3 \pm 0.5$ & $18.3 \pm 0.5$ & $18.0 \pm 0.0$ \\
$\begin{array}{c}\text { O-carboxy } \\
\text { methyl chitosan }\end{array}$ & $\underline{14.0 \pm 0.0}$ & $\underline{13.6 \pm 0.5}$ & $\underline{28.3 \pm 0.5}$ & $\underline{26.0 \pm 0.0}$ & $\underline{27.0 \pm 0.0}$ \\
\hline
\end{tabular}

Data represented the means of three replicates; \pm S.D. Underlined data represented the most active polymer.

The treatment of liver carcinoma cell line (HEPG-2) with tested compounds for $48 \mathrm{~h}$ markedly decreased the viable cell numbers of tested liver carcinoma cell lines with $\mathrm{IC}_{50}$ at $31.5 \mathrm{mg} / \mathrm{ml}$ and $31.75 \mathrm{mg} / \mathrm{ml}$ for chitosan and
O-carboxymethyl chitosan respectively (Table 2). The toxicities of chitosan and Ocarboxymethyl chitosan on normal human fibroblast cells were negligible.

Table (2): Cytotoxicity of chitosan and O-carboxy methyl chitosan against HEPG-2 cell line and WISH 38

\begin{tabular}{ccccc}
\hline \multirow{2}{*}{$\begin{array}{c}\text { Concentration } \\
\text { mg/ml }\end{array}$} & \multicolumn{4}{c}{ Mean of Cell viability \% } \\
\cline { 2 - 5 } & HEPG- & WISH 38 & O-carboxymethyl chitosan \\
\cline { 2 - 5 } & $43.2 \pm 0.039^{\mathrm{e}}$ & $60.5 \pm 0.043^{\mathrm{e}}$ & $44.4 \pm 0.015^{\mathrm{e}}$ & $60 \pm 0.019^{\mathrm{e}}$ \\
250.0 & $52.1 \pm 0.019^{\mathrm{d}}$ & $66.4 \pm 0.05^{\mathrm{d}}$ & $52.6 \pm 0.035^{\mathrm{d}}$ & $65.4 \pm 0.081^{\mathrm{d}}$ \\
12.5 & $78.6 \pm 0.081^{\mathrm{c}}$ & $71.0 \pm 0.018^{\mathrm{c}}$ & $62.5 \pm 0.026^{\mathrm{c}}$ & $72 \pm 0.05^{\mathrm{c}}$ \\
6.25 & $88.4 \pm 0.063^{\mathrm{b}}$ & $83.3 \pm 0.062^{\mathrm{b}}$ & $85.5 \pm 0.018^{\mathrm{b}}$ & $86.7 \pm 0.052^{\mathrm{b}}$ \\
0.0 & $100 \pm 0.053^{\mathrm{a}}$ & $100 \pm 0.05^{\mathrm{a}}$ & $100 \pm 0.053^{\mathrm{a}}$ & $100 \pm 0.05^{\mathrm{a}}$ \\
F & 918294.39 & 1823442.5 & 1818439.8 & 1886546.8 \\
P-value & 0.000 & 0.000 & 0.000 & 0.000 \\
IC50 & $\underline{31.5 \mu \mathrm{g} / \mathrm{ml}}$ & -- & $\underline{31.75 \mu \mathrm{g} / \mathrm{ml}}$ & -- \\
\hline
\end{tabular}

Data represents the means of three replicates; \pm S.D. Means with the same letters are not significantly different at $P \leq 0.05$. IC50 value = the concentration agent required to produce $50 \%$ inhibition of cell growth. 
There was decrease in the wound area throughout the experimental period in all groups. However, the reduction in the wound area in the ointment base treated group (negative control) was less dramatic when compared to the treated groups. For the Ocarboxymethyl chitosan treated group, a sharp decrease in the wound area was observed between the $1^{\text {st }}$ and $10^{\text {th }}$ day after treatment while a gradual reduction in the wound area was recorded for fusidic acid and chitosan ointment treated groups. Hundred percent wound healing was recorded in Ocarboxymethyl chitosan treated group by $14^{\text {th }}$ day post- treatment, where $49 \%$ wound healing was observed in the ointment base treated group, and $100 \%$ healing was obtained in the fusidic acid and chitosan treated groups by day $19^{\text {th }}$. Throughout the experiment, the percentage of wound healing in the ointment base treated group was lower than those of Ocarboxymethyl chitosan, chitosan and fusidic acid treated groups (Table 3; Fig. 5).

Table (3): Effect of topical application of chitosan and O-carboxymethyl chitosan ointments on the percentage of artificial wound contraction of tested mice groups.

\begin{tabular}{ccccccccc}
\hline \multirow{2}{*}{$\begin{array}{c}\text { Days after } \\
\text { treatment }\end{array}$} & \multicolumn{6}{c}{ Chitosan of wound's diameter \& percentage of wound contraction } \\
\cline { 2 - 9 } & $\mathrm{mm}^{2}$ & $\%$ & $\mathrm{~mm}^{2}$ & $\%$ & $\mathrm{~mm}^{2}$ & $\%$ & $\mathrm{~mm}^{2}$ & $\%$ \\
\hline 0 & $110 \pm 2.53$ & 0 & $110 \pm 2.53$ & 0 & $110 \pm 1.7$ & 0 & $110 \pm 1.6$ & 0 \\
$5^{\text {th }}$ & $91 \pm 1.1^{*}$ & 17.2 & $50 \pm 2.9^{*}$ & 54.5 & $90 \pm 1.5^{*}$ & 18.1 & $100 \pm 2.7$ & 9.0 \\
$10^{\text {th }}$ & $52 \pm 1.77 *$ & 52.7 & $25 \pm 3.5^{*}$ & 77.2 & $63 \pm 1.3^{*}$ & 42.7 & $70 \pm 1.5^{*}$ & 36.6 \\
$14^{\text {th }}$ & $30 \pm 2.67 *$ & 72.7 & $0 \pm 0.0 *$ & 100 & $35 \pm 1.6^{*}$ & 68.1 & $66 \pm 1.9 *$ & 40 \\
$17^{\text {th }}$ & $0 \pm 0.0 *$ & 100 & $0 \pm 0.0 *$ & 100 & $20 \pm 1.1^{*}$ & 81.8 & $50 \pm 1.2^{*}$ & 54.5 \\
$19^{\text {th }}$ & $0 \pm 0.0 *$ & 100 & $0 \pm 0.0 *$ & 100 & $0 \pm 0.0 *$ & 100 & $34 \pm 1.7^{*}$ & 69 \\
$21^{\text {st }}$ & $0 \pm 0.0 *$ & 100 & $0 \pm 0.0 *$ & 100 & $0 \pm 0.0 *$ & 100 & $21 \pm 1.34^{*}$ & 80.9 \\
$23^{\text {rd }}$ & $0 \pm 0.0 *$ & 100 & $0 \pm 0.0 *$ & 100 & $0 \pm 0.0 *$ & 100 & $0 \pm 0.0 *$ & 100 \\
\hline
\end{tabular}

Significantly different from the values of the control mice at $P \leq 0.05 . \mathrm{mm}^{2}=$ diameter of the wound area; $\%=$ percentage of wound contraction.

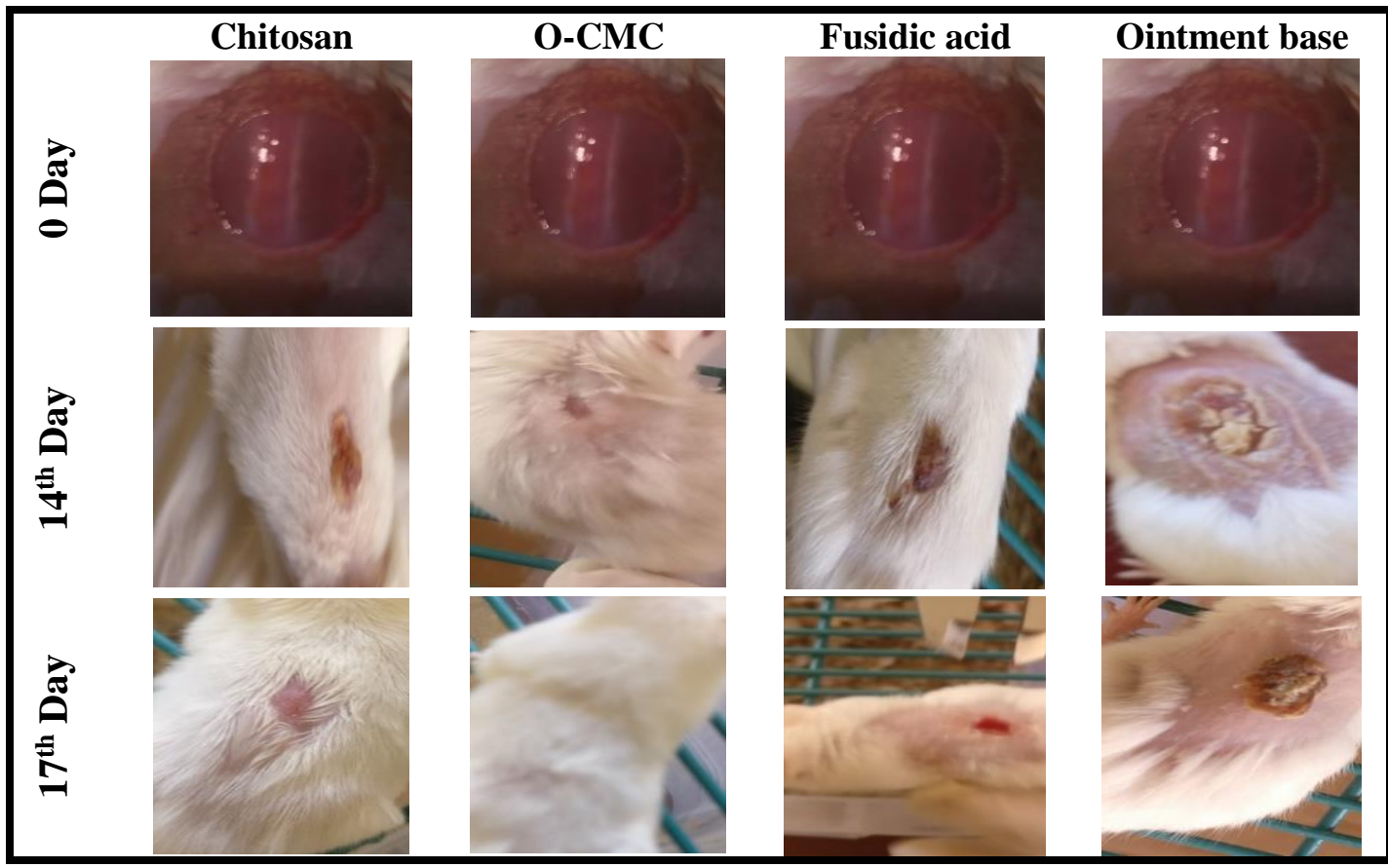

Figure 5: Photographic representation of wound area following topical application of chitosan, O-carboxymethyl chitosan, fusidic acid and ointment base treatments on artificial wound of tested mice groups on the days 0,14 and 17 of treatment. 
Improvement tests for biopolymers effectiveness and safety were achieved by histopathological studies on healthy mice skin as a negative control and on infected one as a positive control. Skin section for healthy mice skin tissues showed normal epidermis as the keratinized fibers of stratum corneum were regularly arranged, appeared condensed

In comparison with control, O-carboxymethyl chitosan treated skin section possessed no significant toxic effects; the skin tissues appeared with normal epidermis as the keratinized fibers of stratum corneum were regularly arranged, appeared condensed without any disruption and the dermis appeared normal with minimal inflammatory cellular infiltrate as shown in fig. 6C. On the without any disruption and the dermis appeared normal with normal fibroblasts as shown in fig. 6A, while skin tissues of infected mice (untreated) as in fig. 6B showed loose and disrupted keratinized fibers and the dermis appeared abnormal with chronic inflammatory cellular infiltrate mainly formed of lymphocytes and plasma cells.

other hand, fusidic acid ointment-treated skin section and chitosan preparing ointmenttreated skin section possessed abnormal epidermis as the keratinized fibers of stratum corneum still showed some disruptions and the dermis showed edema with some inflammatory cellular infiltrate of lymphocytes as illustrated in fig. 6D \& $6 \mathbf{E}$.

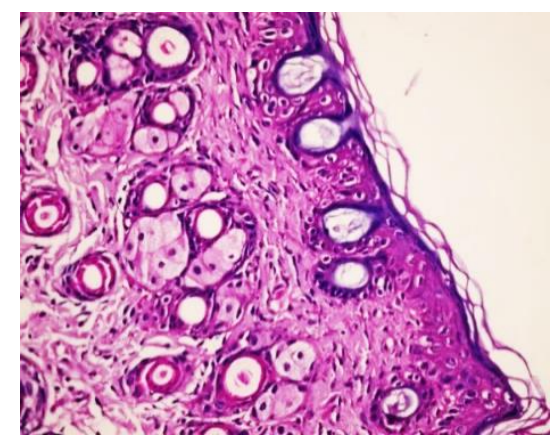

(A)

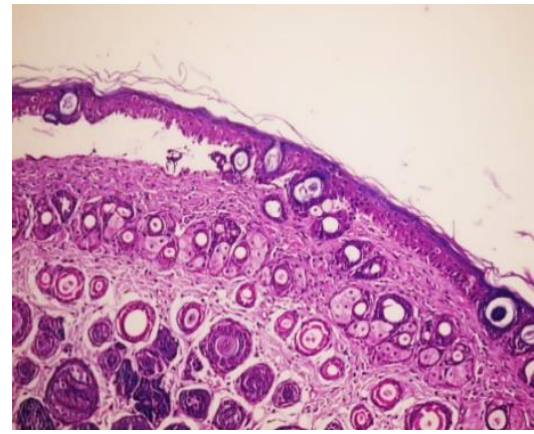

(B)

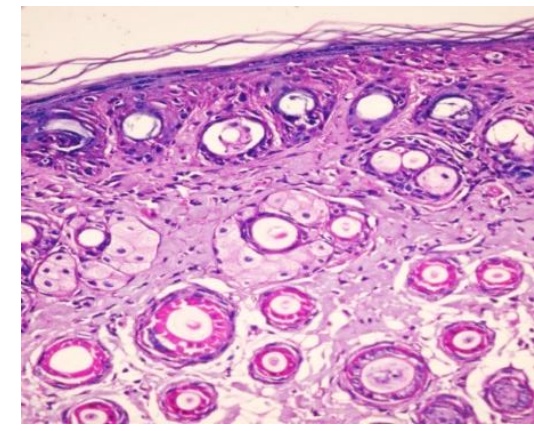

(C)

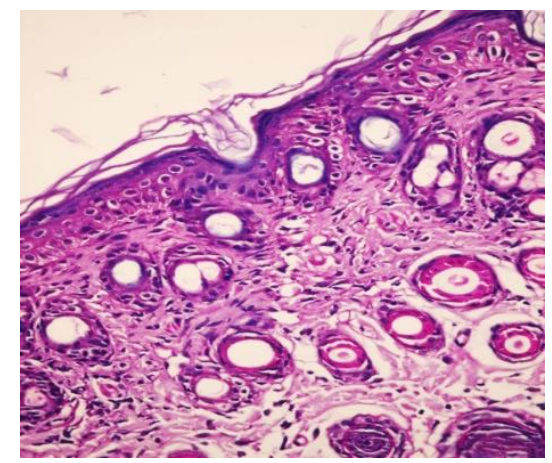

(D)

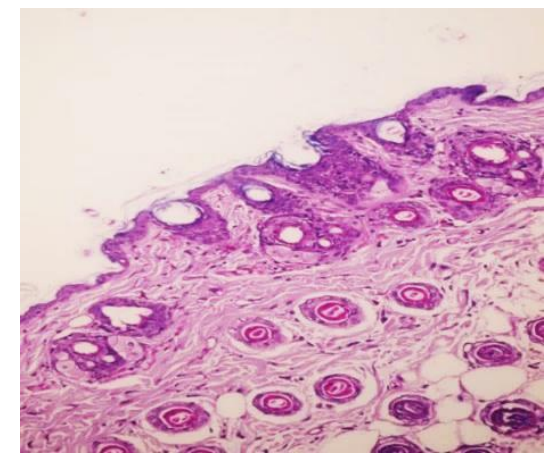

(E)

Figure 6: Histopathological effects of polymers treatments for $P$. aeruginosa infection on mice skin tissues. (A)Negative control: healthy skin; (B) Positive control: infected non-treated skin; (C) O-carboxymethyl chitosan- treated, healed skin; (D) Chitosan- treated, healed skin and (D) Fusidic acid-treated healed skin.

\section{Discussion}

In this study, we prepared some modified natural polymers to study their effect on multidrug-resistant pathogenic bacteria, isolated from wounds. The natural polymer (chitin) was prepared from crab shells. Crab shell waste is an excellent source of chitosan (Gaikwad et al., 2015). Crab shell is made up of three basic components. These are chitin, 
protein and a calcium salt of which chitin is most important for scientific studies. Chitin is a fairly completely acetylated polysaccharide in nature, being the second after cellulose (Adole and Omogbai, 2012).

The main aim of this study was the extraction of chitosan from crab shell waste. The raw materials used in this work were the exoskeleton of crabs which collected from local restaurants in the city of Tanta, Egypt. The shells were grounded and sieved. Chitosan extracted from crab shell by using acid and alkaline treatments (demineralization, deproteinization, discoloration) followed by deacetylation. The chitosan end-product needed to be highly purified, as the residual proteins, minerals or pigments can cause serious effects. After the demineralization, deproteinization and discoloration, it was found that the chitin content of crab was $19.7 \%(16.3 \mathrm{~g})$ of the dry weight. As the reaction of chitin deacetylation is more aggressive due to high alkalinity and temperature employed, the chitosan yield from the chitin was found to be $74.2 \%$ (12.1 g). Arrouze et al. (2017) recorded that the chitin content of the dry weight of crabs, varies between 13 and $42 \%$.

Crystallinity of chitosan was generated from hydrogen bond between corresponding hydroxyl and $\mathrm{N}$-acetyl groups. Each crystalline peak characterizes crystallographic structure, which is generated from parallel and antiparallel alignments of polymeric chains or sheets. The crystallinity index (CI) can be calculated on the basis of X-ray diffractograms (Chauhan, 2012). XRD has done to confirm the formation of chitosan and to determine the nature of chitosan powder. The XRD pattern of chitosan exhibited broad diffraction peaks at $2 \theta=10^{\circ}$ and $20^{\circ}$ which are typical fingerprints of semi-crystalline chitosan. Smilar results were attained by Prashant \& Tharanathan, 2005.

According to the infrared spectroscopy of chitin, the degree of acetylation was $99.12 \%$. If the degree of acetylation of chitin is greater than $100 \%$, this indicated the presence of some mineral residues in the chitin. In other studies, the DA values for chitin isolated from different organisms were determined to be $102 \%$ for cicada sloughs, $104 \%$ for rice field crab shells, $87 \%$ for bumblebees, $99 \%$ for shrimp and $151 \%$ for a crude chitin from crabs (Sajomsang \& Gonil, 2010). According to the infrared spectroscopy of chitosan, the degree of deacetylation was $86.6 \%$. Degree of deacetylation (DD) is an important property that affects the biodegradability activity (Fernandez-Kim, 2004), as this parameter has effects on solubility, chemical reactivity and biodegradability. The antimicrobial activity of chitosan increases with increasing the degree of deacetylation, due to the increasing number of ionized amino groups. Degree of deacetylation may range from 30 to 95\% according to the source and preparation procedures (Islam et al., 2011a).

In this study, water-soluble chitosan derivative has been prepared by introducing carboxymethyl group in the macromolecular chain of chitosan. Carboxymethyl chitosan has been studied because its ease of synthesis, ampholytic character and possibilities of ample of applications. Carboxymethylation can be ensued through reductive alkylation and direct alkylation. The substitution can occur at $\mathrm{N}$, or $\mathrm{O}$ or both atoms. The synthetic transformation steps performed are often relatively simple, exploiting the difference in the nucleophilities of primary amine group at $\mathrm{C}-2$ versus the two hydroxyl groups at C-3 and C-6. From the literature, it was found that the greater reactivity of amino groups rather than hydroxyl groups (Mohy Eldin et al., 2008). So, in this study, we try to increase the antibacterial activity of chitosan by attaching the carboxymethyl group directly on the hydroxyl group of polysaccharides. Ocarboxymethyl chitosan has been synthesized by direct alkylation, as some of the $-\mathrm{OH}$ groups of chitosan were substituted by $\mathrm{CH} 2 \mathrm{COOH}$ groups.

O-carboxymethyl chitosan was characterized by FT-IR spectroscopy. The infrared spectrum of O-carboxymethyl chitosan showed the intrinsic peak of $-\mathrm{COOH}$ group at $1741 \mathrm{~cm}^{-1}$. The bands at 1154 and $1029 \mathrm{~cm}^{-1}$ were corresponding for $(-\mathrm{C}-\mathrm{O})$ group. The peaks at 1624 and $1506 \mathrm{~cm}^{-1}$ were corresponding for $(-$ 
$\mathrm{NH}^{+}$) group. Similar results have been recorded by Mourya et al., 2010.

The antibacterial properties of the chitosan and O-carboxy methyl chitosan were compared for their effectiveness against wound pathogens: two multidrug-resistant Gram-positive bacteria (Staphylococcus aureus and Streptococcus pyogenes) and three multidrug-resistant Gram-negative bacteria (Pseudomonas aeruginosa, Escherichia coli and Proteus mirabilis).

The results of the antibacterial screening assay of chitosan showed that O-carboxymethyl chitosan recorded a higher antibacterial activity than chitosan. This would suggest that an increase in the solubility of chitosan molecule and a substitution with carboxymethyl group led to an increase in the antibacterial activity. Chitosan and Ocarboxymethyl chitosan were more effective against Gram-negative bacteria than Grampositive bacteria which may be attributed to the difference in the physiological cell wall structure of the two strains. Similar results have been recorded by Islam et al. (2011b).

The cell wall of gram-negative bacteria is made up of a thin layer of peptidoglycan and an outer membrane constituted of lipopolysaccharide, lipoprotein, and phospholipids. Outer membrane contains polyanionic lipopolysaccharide stabilized by divalent cations, such as $\mathrm{Mg}^{2+}$ and $\mathrm{Ca}^{2+}$ (Clifton et al., 2015). The outer membrane serves as an effective permeability barrier to restrict macromolecules and hydrophobic substances from entering or leaving bacterial cells. The antibacterial mechanisms of chitosan suggested being, the positive charge of the amino group at C-2 resulted in a polycationic structure which can be expected to compete with divalent cations to bind with the predominantly anionic lipopolysaccharides, resulting in disorganizing the outer membrane. The interaction resulted in great alteration in the structure of outer membrane, which caused release of major proportion of proteinaceous materials from the cells. The normal functions of the membrane were disrupted; leakage of intracellular components was promoted and also the transport of nutrients into the cells was inhibited (Goy et al., 2016). On the other hand, Gram-positive bacteria, has a cell wall composed mainly of peptidoglycan, which does not allow the formation of a surface layer.

In the present study, the cytotoxicity of chitosan and O-carboxymethyl chitosan was tested using Sulfo-Rhodamine-B stain (SRB) colorimetric assay method on liver cancer cell line (HEPG2). The results showed that the inhibition rate increased with increasing the compounds concentrations in the culture medium where $\mathrm{IC}_{50}$ was found to reach 31.5 $\mathrm{mg} / \mathrm{ml}$ and $31.75 \mathrm{mg} / \mathrm{ml}$ for chitosan and Ocarboxymethyl chitosan respectively. The toxicity of chitosan and O-carboxymethyl chitosan on normal human fibroblast cells were negligible. The potential cytotoxic effects of chitosan and its derivatives had been studied in vivo and in vitro by Lin et al. (2007). The authors evaluated the cytotoxic effects of chitosan derivatives were due to the increase in secretion of interleukin 1 and 2 which caused maturation and infiltration of cytolytic T-lymphocytes.

In this study, the effects of chitosan and Ocarboxymethyl chitosan on wound healing were studied in vivo. The results showed that O-carboxymethyl chitosan treatment group significantly accelerated the healing process of artificial wound. Animals with Ocarboxymethyl chitosan treatment had shorter healing time than the control group and had better looking appearance of the new skin. Ocarboxymethyl chitosan could effectively accelerate wound healing and reduce scar formation.

Carboxymethyl chitosan is a water soluble chitosan derivative and functional biomaterial which possesse many favourable biological properties such as biocompatibility, diodegradability and bioactivity (He et al., 2016). They effectively accelerate wound healing and reduce scar formation. They effectively promote wound healing by accelerating collagen synthesis and the propagation of fibroblasts ( Peng et al., 2011). The mechanism by which chitosan stimulates fibroblast growth has been recorded by Kojima et al., 2004. Chitosan accelerated 
fibroblast proliferation by forming polyelectrolyte complexes with serum components such as heparin or platelet-derived growth factor.

\section{Conclusion}

On the basis of the present study, it was concluded that the exoskeletons of crabs which are considered an industrial waste creating an environmental pollutant can be transformed into high valued products by extraction of chitosan from chitin that is present in them. Water-soluble chitosan derivative, O-carboxymethyl chitosan has been prepared by introducing carboxymethyl group into the macromolecular chain of chitosan. The antibacterial activity of chitosan was increased by grafting carboxymethyl group into its backbone chains. Chitosan and Ocarboxymethyl chitosan had stronger effect on multi-drug resistant Gram-negative bacteria rather than Gram-positive ones. However, grafting the carboxymethyl group on the backbone of chitosan had successed in increasing its antibacterial activity, it didn't affect its cytotoxicity. Chitosan and Ocarboxymethyl chitosan were highly active and safe in the treatment of wound infection.

\section{References}

Adole T, Omogbai BA. 2012. Antibacterial Effect of Crab Shell Extract on Klebsiella pneumonia and Proteus mirabilis. J. of Pharmacy and Bioliolgical Sciences, 1(1):1-6.

Arrouze F, Essahli M, Rhazi M, Desbrieres J, Tolaimate A. 2017. Chitin and chitosan: Study of the possibilities of their production by valorization of the waste of crustacean and cephalopods rejected in Essaouira. Journal of Materials and Environmental Sciences, 8(7):2251-2258

Bancroft J.; Stevens A. \& Turner D., 1996: Theory and practice of histological technique. J. Histopathology and Microbiol Infect. 25: 98104.

Baxter A, Dillon M, Taylor KDA, Roberts GAF. 1992. Improved method for I.R. determination of the degree of $\mathrm{N}$-acetylation of chitosan. Int. J. Biol. Macromol., 14(3): 166-169.
Chauhan A. 2012. XRD Elaborates the Metamorphosis in Graft Copolymers. Journal of Analytical and Bioanalytical Techniques, 3(5) DOI: 10.417212155-9872.1000148

Clifton LA, Skoda MW, Le Burn AP, Ciesielski F, Kuzmenko I, Holt SA, Lakey JH. 2015. Effect of divalent cation removal on the structure of gram-negative bacterial outer membrane, Longmuir, 31(1): 404-412

Escarcega Galaz AA, Cruz-Mercado JL, Cervantes JL et al. 2018. Chitosan treatment for skin ulcers associated with diabetes. Saudi Journal of Biological Sciences, 25(1): 130-135

Fernandez-kim SO.2004. Physicochemical and functional properties of crawfish chitosan as affected by different processing protocols. Dissertation of MSc.: Graduate Faculty of Seoul National University; p. 107.

Florescu SA, Calistru PI, Smadu S, Codreanu D, Popescu AM, Popescu CP, Ceausu E. 2017. Mortality causes in infectious diseases. Romanian Society of Legal Medicine, $25(1): 20-23$

Gaikwad BV, Koli JM, Desai AS. 2015. Isolation and characterization of chitosan from crab (Scylla serrate) shell waste. International Journal of Sciences \& Applied Research, 2(8): 78-84.

Goy RC, Morais STB, Assis OBG. 2016. Evaluation of the antimicrobial activity of chitosan and its quaternized derivative on E.coli and S. aureus growth. Brazilian Journal of Pharmacognosy, 26: 122-127

He, G., Chen. X., Yin, Y., Cai, W., Ke, W., Kong, Y. and Zhen, H. (2016): Preparation and antibacterial properties of O-carboxymethyl chitosan/lincomycin, Polymer Edition, 27(4): 370-384.

Inmaculada A, Ruth H, Angeles H. 2010. Chitosan Amphiphilic Derivatives: Chemistry and Applications. Current Organic Chemistry, 14(3): 308-33.

Islam MM, Masum SM, Rahman MM, Molla AT, Shaikh AA, Roy SK. 2011. Preparation of chitosan from shrimp shell and investigation of its properties. International Journal of Basic \& Applied Sciences, 11(1): 77-88

Islam MMD, Masum SMD, Mahbub KR. 2011 b. In vitro antibacterial activity of shrimp chitosan 
against Salmonella paratyphi and Staphylococcus aureus. Journal of Bangladesh Chemical Society, 24(2): 185-190.

Kojima K.; Okamoto Y.; Kojima K.; Miyatake K.; Fujise H.; Shigemasa Y., \& Minami S., 2004. Effects of chitin and chitosan on collagen synthesis in wound healing. Journal of Veterinary Medical Science, 66: 1595-1698.

Lin, S., Chan, H., Shen, F., Chen, M., Wang, Y. and $Y u, C$. (2007): Chitosan prevents the development of AOM-induced aberrant crypt foci in mice and suppressed the proliferation of AGS cells by inhibiting DNA synthesis. J Cell Biochem., 100: 1573-1580.

Liu S, Sun J, Yu L, Zhang C, Bi J, Zhu F, Qu M, Jiang $C$, Yang $Q$. 2012. Extraction and characterization of chitin from the beetle Holotrichia parallela motschulsky. Molecules, 17(4): 4604-4611

Liu, H., Wang, C., Li, C., Qin, Y., Wang, Z., Yang, F., Li, Z., and Wang J. (2018): A functional chitosan-based hydrogel as a wound dressing and drug delivery system in the treatment of wound healing. RSC Adv., 8: 7533-7549.

Majtan J, Bilikova K, Markovic O, Grof J, Kogan G, Simuth J. 2007. Isolation and characterization of chitin from bumblebee (Bombus terrestris). Int. J. Biol. Macromol. 40(3): 237-241.

Mohy Eldin MS, Soliman EA, Hashem AI, Tamer TM. 2008. Chitosan Modified Membranes for Wound Dressing Applications: Preparations, Characterization and Bio-Evaluation. Trends Biomater. Artif. Organs, 22: 154-164.

Mourya VK, Inamdar NN, Tiwari A. 2010. Carboxymethyl chitosan and its applications. Advanced Matterials letters, 1(1): 11-33

Munoz-Bonilla A, Cerrada M. Fernandez-Garcia M. 2014. Polymeric Materials with Antimicrobial Activity: From Synthesis to Applications, Royal Society of Chemistry Cambridge, UK pp 75-96

Niksa L.; Genevieve M.; Edouard Reyes G.; Thomas L.; Odile C. \& David M., 2010. Cutaneous re-epithelialization and wound contraction after skin biopsies in rabbits: a mathematical model for healing and remodelling index. J. VETERINARSKI 80 (5). 637- 652 .
No HK, Lee SH, Park NY, Meyers SP. 2003. Comparison of physichemical, binding, and antibacterial properties of chitosans prepared without and with deproteinization process. $J$ Agric Food Chem, 51: 7659-7663.

Partulea, V., Ostafe, V., Borchard, G. and Jordon, $O$. (2015): Chitosan as a starting material for wound healing applications. European Journal of pharmaceutical and BioPharmaceutics, 97: 417-426.

Peng S. K.; Liu W. S.; Han B. Q.; Chang J.; Li M. $Y$. \& Zhi X., 2011. Effects of carboxymethylchitosan on wound healing in vivo and in vitro. Journal of Ocean University of China, 10: 369-378.

Pipkin FB. 1984. Medical statistics made easy. Churchill Livingstone Edinburgh London Melpourine and New York, pp. 137.

Prashant HKV, Tharanathan RN. 2005. Depolymerized products of chitosan as potent inhibitors of tumor-induced angiogenesis. Biochem Biophy Acta., 1722(1): 22-9

Pridham T, Lindenfelser L, Shotwell O, Stodola F, Benedict R, Foley C, Jacks P, Zaumeyer W, Perston W. 1956. Antimicrobial activity of some plant extracts. J. Phytopathology, 46: 568-588.

Sajomsang W, Gonil P. 2010. Preparation and characterization of $\alpha$-chitin from cicada sloughs. Materials Science and Engineering: C, 30(3): 357-363.

Skehan P, Stroreng R. et al. 1990. New Colorimetric Cytotoxicity Assay for Anticancer- drug screening. Journal of National Cancer Institute, 82: 1107-1112.

Xing, L., Fan, Y., Zhou, T., Gong, J., Cui, L., Cho, K., Choi, Y., Jiang, H., and Cho, C., (2018): Chemical Modification of Chitosan for Efficient Vaccine Delivery. Molecules, 23(2): 229-241.

Zhu A, Liu J, Ye W. 2006. Effective loading and controlled release of camptothecin by $O$ carboxymethyl chitosan aggregates. J. Carbohydr. Polym., 63:89-96 